The maxima of emission of flames are to be regarded as due to pure radiation of temperature for which the chemical process is non-essential.-Wiedenıann's Annalen, No. 11, 1893.

\title{
ON THE CONDITION OF MATTER NEAR THE CRITICAL POINT.
} BY B. GALITZINE.

The following is a summary of the results obtained by the author:-

1. The temperature $t_{c}$ of the actual appearance of the meniscus on cooling must be lower, and even considerably so than the true critical temperature $\mathrm{T}_{c}$ of the substance. Accordingly the optical method, at any rate in its ordinary form-observation of tho formation of mist-must lead to incorrect results for the critical temperature.

2. With very slow and regular cooling the frequently discussed peculiar formation of mist is no necessary condition of the phenomenon.

3. The temperature at which the meniscus actually appears, and the temperature $t_{c}{ }^{\prime}$ at which the last traces of want of homogeneity disappear, must be assumed to be independent of the quantity of substance in the tube.

4. The density $\rho$ of a liquid (in contact with its vapour) and the density $\delta$ of its saturated vapour change at exactly the same temperature with the time, and with frequent heating beyond the critical temperature, in which $\rho$ decreases and $\delta$ increases.

5. Both magnitudes are therefore not completely and unequivocally defined by the temperature alone.

6. At temperatures which lie considerably higher than the critical temperature, a body at almost exactly the same temperature may have two (or perhaps more) different densities. The differences of density may amount to 21-25 per cent.

7. The remarkable anomalies observed by various experimenters, which are with difficulty brought into harmony, may be very well recognized and justified on the basis of the modern views as to molecular processes in liquid and vapour.-Wiedemann's Annalen, No. 11, 1893.

\section{NOTE ON THE ATOMIC WEIGHT OF CARBON. BY J. ALFRED WANKLYN.}

An investigation which has occupied me for the greater part of the year has yielded the following remarkable result. There is a series of hydrocarbons the successive members of which rise in molecular weight-not by $\mathrm{CH}_{2}=14$-but by $\frac{1}{2}\left(\mathrm{CH}_{2}\right)=7$. If this result cannot be overturned, the consequence follows that the atomic weight of carbon is 6 . 